\title{
A comparative analysis of errors in inhaler technique among COPD versus asthma patients
}

This article was published in the following Dove Press journal:

International Journal of COPD

\section{Birsen Ocakli' \\ Ipek Ozmen' \\ Eylem Acartürk Tunçay' \\ Sinem Gungor' \\ Hilal Altinoz' \\ Nalan Adiguzel' \\ Zafer Ali Sak ${ }^{2}$ \\ Gokay Gungor' \\ Zuhal Karakurt ${ }^{\prime}$ \\ Peri Arbak ${ }^{3}$}

'University of Health Sciences, Sureyyapasa Chest Diseases and Thoracic Surgery Training and Research Hospital, Istanbul, Turkey; ${ }^{2}$ Department of Chest Diseases, Harran University, Faculty of Medicine, Sanliurfa, Turkey; ${ }^{3}$ Department of Chest Diseases, Duzce University, Faculty of Medicine, Duzce, Turkey
Correspondence: Birsen Ocakli University of Health Sciences, Sureyyapasa Chest Diseases and Thoracic Surgery Training and Research Hospital, 34854 Maltepe, Istanbul, Turkey

Tel +9021642I 4200

$\mathrm{Fax}+902164214110$

Email birsenocakli@hotmail.com
Purpose: This study was designed to evaluate errors in inhaler technique in COPD vs asthma patients and to investigate the association of poor inhaler technique with patient demographics and clinical variables.

Patients and methods: A total of 509 adult patients with COPD $(n=328)$ or asthma $(n=181)$ who were currently using an inhaler device were included in this study. Data on patient demographics, duration of disease, type and duration of inhaler therapy, and assessment of inhaler technique were recorded.

Results: Metered dose inhaler (MDI) was the most common type of inhaler used by a similarly high percentage of patients in both COPD (83.2\%) and asthma (77.3\%) groups. Failure to exhale before inhaling through device $\left(75.8 \%\right.$ and $68.5 \%$ for MDIs; $73.2 \%$ and $71.8 \%$ for Aerolizer ${ }^{\mathbb{B} /}$ Handihaler $^{\mathbb{R}} ; 53.1 \%$ and $66.7 \%$ for Turbuhaler ${ }^{\mathbb{R}}$ ) was the most common error in inhaler technique, in both COPD and asthma groups. Device-specific errors in inhaler techniques were more common in asthma patients as compared with COPD patients, particularly for MDIs ( $P$-values ranged from 0.046 to 0.0005 ), as associated with female gender (failure to press the buttons on both sides of Aerolizer ${ }^{\circledR} /$ Handihaler $^{\circledR}, P=0.006$ ), shorter duration of disease (failure to hold MDI or head in a vertical position, $P<0.001$, and to keep Turbuhaler ${ }^{\mathbb{B}}$ upright, $P=0.005$ ), and shorter duration of inhaler usage (failure to hold head in a vertical position during MDI usage, $P=0.006$, and to keep Turbuhaler ${ }^{\circledR}$ upright, $P=0.012$ ).

Conclusion: In conclusion, our findings revealed that errors in inhaler technique in terms of inhalation maneuvers and device handling were similarly common in COPD and asthma patients. Errors in certain device handling maneuvers, particularly with MDIs, were more common among asthma patients than among COPD patients and associated with female gender and shorter durations of disease and inhaler therapy.

Keywords: chronic obstructive pulmonary disease, asthma, inhaler therapy, inhaler technique, metered dose inhalers, dry powder inhalers

\section{Introduction}

Inhaled therapy is a mainstay in the management of asthma and COPD. ${ }^{1-3}$ Metered dose inhalers (MDIs), dry powder inhalers (DPIs), and nebulizers are the most common inhaler devices used to administer aerosolized medication in routine respiratory practice. $^{1-5}$

Optimal inhaler technique depends on correct preparation and handling of the device before inhalation and an optimal inhalation technique. ${ }^{3}$ Although MDIs are considered to be more difficult to use than DPIs, ${ }^{3,6-9}$ errors in inhaler technique are very common among COPD and asthma patients in daily real-life practice. ${ }^{3,5,10-16}$ Poor inhaler technique has been associated with inadequate drug delivery to the lungs and thus with poor disease control and worse disease outcomes. ${ }^{1-3,9,14,17-19}$ 
Recent global position documents from the Global Initiative for Asthma (GINA) and GOLD both highlight the critical importance of assessing inhaler technique to guide appropriate inhaler prescribing and correcting poor inhalation technique before escalating drug therapy. ${ }^{20,21}$

However, published data on the interaction between patient, device, and inhaler technique are considered to be insufficient and inconsistent. ${ }^{19}$ Moreover, comparison of inhaler techniques in COPD vs asthma patients also revealed inconsistent findings with similar rate of errors ${ }^{14,17,19}$ or higher odds of incorrect inhaler technique in COPD patients than in asthma patients, ${ }^{8}$ after adjusting for age, gender, and level of education. Indeed, older age and higher prevalence of comorbidities in COPD patients have been associated with a higher likelihood of poor inhaler technique as compared with asthma patients. ${ }^{3,8}$ In addition, discordance between self-assessment and medical supervision in terms of rates of correct inhaler technique has been noted in COPD and asthma patients, while COPD patients were reported to be more uncertain with MDI technique on self-assessment and to make more errors during direct observation when compared to asthmatics. ${ }^{22}$

Being addressed in a limited number of studies to date, the differences between asthma and COPD in terms of etiology, symptoms, pathophysiology, consequences of inflammation, response to therapy, and clinical course may affect the inhaler performance of patients. Thus, comparison of inhaler technique among COPD and asthma patients may help to better understand how to improve the use of inhalers. This study was therefore designed to comparatively evaluate errors in inhaler technique in COPD vs asthma patients and to investigate the association of poor inhaler technique with patient demographics and clinical variables.

\section{Material and methods}

\section{Study population}

A total of 509 adult patients with COPD $(n=328)$ or asthma $(n=181)$ who were currently using at least one inhaler device for at least 1 month were included in this cross-sectional, observational study conducted at a tertiary pneumology outpatient clinic from February to May 2018. MDI, Aerolizer ${ }^{\circledR /}$ Handihaler $^{\circledR}$, Diskus ${ }^{\circledR}$, and Turbuhaler ${ }^{\circledR}$ were assessed in this study as the most commonly used devices of those available in Turkey. Patients aged $>18$ years and diagnosed with asthma according to the GINA ${ }^{20}$ or with COPD according to the GOLD ${ }^{21}$ were included in the study. Use of inhaler therapy for less than a month, lack of attendance of regular control visits, confirmed or suspected pregnancy, breastfeeding, allergy, sensitivity or intolerance to asthma or COPD therapy, and being on nebulizer therapy per se were the exclusion criteria of the study.

Written informed consent was obtained from each subject following a detailed explanation of the objectives and protocol of the study, which was conducted in accordance with the ethical principles stated in the Declaration of Helsinki and approved by the University of Health Sciences, Sureyyapasa Chest Diseases and Thoracic Surgery Training and Research Hospital Ethics Committee (date of approval: February 5, 2018, protocol number: 018).

\section{Data collection}

Data on patient demographics (age, gender), duration of disease, type and duration of inhaler therapy, and assessment of inhaler technique (correct, incorrect) were recorded in COPD and asthma groups. The inhaler technique for each device was evaluated through direct observation of patient's performance using checklists developed in-house specifically for each inhaler device based on the manufacturers' instructions and recommendations for correct implementation of inhalers provided by Turkish Thoracic Society Patient Information Handbook on Asthma ${ }^{23}$ and Turkish Thoracic Society National Asthma Diagnosis and Management Guidelines. ${ }^{24}$ The same interviewer, who was an experienced respiratory technician blinded to diagnosis group, registered whether each step was performed properly and in an adequate order, and errors in inhaler technique were compared between COPD and asthma groups. Errors in maneuvers that significantly differed between patients with COPD and asthma were further analyzed in relation to demographic and disease-related characteristics.

\section{Statistical analysis}

Statistical analysis was performed using IBM SPSS Statistics for Windows, version 21.0 (IBM Corporation, Armonk, NY, USA). Chi-squared test was used to analyze the comparison of categorical data between COPD and asthma groups and to analyze the influence of gender on errors in inhaler techniques that differed between COPD and asthma groups. Student's $t$-test and Mann-Whitney $U$ test were used for sub-analysis of errors in inhaler techniques that differed between COPD and asthma groups in terms of age and duration of disease and inhaler therapy. Data were expressed as mean SD, percent (\%), and minimum-maximum where appropriate. $P<0.05$ was considered statistically significant. 


\section{Results}

\section{Demographic and clinical characteristics in COPD and asthma groups}

The COPD group was associated with older patient age (mean SD 64.6 [10.3, 29-89] vs 56.0 [14.5, 17-90] years, $P<0.001)$ and higher percentage of males $(65.2 \%$ vs $22.7 \%$, $P<0.001$ ) than the asthma group (Table 1).

MDI was the most common type of inhaler used by a similarly high percentage of patients in both COPD (83.2\%) and asthma (77.3\%) groups, followed by Aerolizer ${ }^{\circledR} /$ Handihaler $^{\circledR}$ (75.9\%) type of inhalers in COPD group and by Diskus ${ }^{\circledR}$ $(41.4 \%)$ in the asthma group (Table 1$)$.

\section{Errors in inhaler technique in COPD and asthma groups}

In both COPD and asthma patients, errors in inhalation maneuvers were the most prevalent errors, including failure to exhale before inhaling through device $(75.8 \%$ and $68.5 \%$ for MDIs; $73.2 \%$ and $71.8 \%$ for Aerolizer ${ }^{\circledR} /$ Handihaler $^{\circledR}$; $53.1 \%$ and $66.7 \%$ for Turbuhaler $^{\circledR}$ ) and failure to deeply inhale $(75.0 \%$ and $80.0 \%)$ for Diskus ${ }^{\circledR}$ type inhalers (Table 2).

The most common errors were device-specific errors and were related to shaking the MDI device before use $(51.1 \%$ and $57.3 \%$ ), removing the Diskus ${ }^{\circledR}(50.0 \%$ and $49.2 \%)$, and pressing the buttons on both sides of Aerolizer ${ }^{\circledR} /$ Handihaler $^{\circledR}$ (26.8\% and 52.6\%) (Table 2).

Poorer inhaler technique was noted in asthma patients as compared with COPD patients with higher rate of errors in steps including taking off the inhaler cap (8.1\% vs $14.5 \%$,
$P=0.046)$, holding the MDI in a vertical position (19.4\% vs $9.9 \%, P=0.011$ ), and holding the head in a vertical position $(20.2 \%$ vs $9.9 \%, P=0.007)$ during MDI usage, in pressing the buttons on both sides of the device $(52.6 \%$ vs $26.8 \%$, $P=0.0005)$ and holding breath for 10 seconds $(33.3 \%$ vs $19.5 \%, P=0.012$ ) during Aerolizer ${ }^{\circledR} /$ Handihaler $^{\circledR}$ usage, and keeping the Turbuhaler ${ }^{\circledR}$ upright $(25.6 \%$ vs $6.3 \%, P=0.029)$ (Table 2).

\section{Sub-analysis of errors in inhaler techniques that differed between COPD and asthma groups}

Shorter duration of disease (failure to hold MDI or head in a vertical position, $P<0.001$, and to keep Turbuhaler ${ }^{\circledR}$ upright, $P=0.005$ ) and shorter duration of inhaler therapy (failure to hold head in a vertical position during MDI usage, $P=0.006$, and to keep Turbuhaler ${ }^{\circledR}$ upright, $P=0.012$ ) were associated with increased likelihood of device-specific errors in inhaler techniques in patients with COPD or asthma (Table 3).

Failure to press the buttons on both sides of the Aerolizer ${ }^{\circledR} /$ Handihaler $^{\circledR}$ was more common among females than among males $(42.0 \%$ vs $27 \%, P=0.006)$ with COPD or asthma (Table 3).

\section{Discussion}

Our findings revealed that errors in inhalator technique were very frequent in both COPD and asthma patients. The inhaler techniques of COPD vs asthma patients differed mostly in certain device-specific errors rather than the inhalation maneuvers. Poor inhaler technique in device handling

Table I Baseline characteristics of patients in COPD and asthma groups

\begin{tabular}{|c|c|c|c|}
\hline Patient demographics & COPD $(n=328)$ & Asthma $(n=18 I)$ & $P$-value \\
\hline Age (years), mean (SD, min-max) & $64.6(10.3,29-89)$ & $56.0(\mid 4.5,17-90)$ & $<0.001^{a}$ \\
\hline \multicolumn{4}{|l|}{ Gender, n (\%) } \\
\hline Female & II4 (34.8) & $140(77.3)$ & $<0.00 I^{b}$ \\
\hline Male & $214(65.2)$ & $41(22.7)$ & \\
\hline \multicolumn{4}{|c|}{ Duration (years), mean (SD, min-max) } \\
\hline Disease & $9.5(7.7,0-40)$ & $9.2(9.5,0-46)$ & $0.727^{c}$ \\
\hline Inhaler therapy & $8.0(6.6,0-35)$ & $7.0(7.6,0-40)$ & $0.146^{c}$ \\
\hline \multicolumn{4}{|l|}{ Inhaler type, n (\%) } \\
\hline MDI & $273(83.2)$ & $140(77.3)$ & $0.067^{\mathrm{b}}$ \\
\hline Aerolizer ${ }^{\circledast} /$ Handihaler $^{\circledast}$ & $249(75.9)$ & $69(38.1)$ & $<0.00 I^{\mathrm{b}}$ \\
\hline Diskus $^{\circledR}$ & $78(23.8)$ & $75(4 I .4)$ & $<0.001^{\mathrm{b}}$ \\
\hline Turbohaler ${ }^{\circledast}$ & $34(10.4)$ & $43(23.8)$ & $<0.00 I^{\mathrm{b}}$ \\
\hline Nebulizer & III (33.8) & $32(17.7)$ & $<0.00 I^{\mathrm{b}}$ \\
\hline
\end{tabular}

Notes: a'Student's $t$-test; ' ${ }^{\text {C }}$ i-square test; 'Mann-Whitney $U$ test.

Abbreviation: MDI, metered dose inhaler. 
Table 2 Errors in inhaler technique in COPD and asthma groups

\begin{tabular}{|c|c|c|c|}
\hline \multirow[b]{2}{*}{ Instructions for MDI } & \multicolumn{2}{|c|}{ Patients with errors, n (\%) } & \multirow[t]{2}{*}{ P-value } \\
\hline & COPD $(n=223)$ & Asthma $(n=124)$ & \\
\hline Take off the inhaler cap & $18(14.5)$ & $18(8.1)$ & 0.046 \\
\hline Shake the MDI before use & II $4(5 \mathrm{I} . \mathrm{I})$ & 71 (57.3) & 0.162 \\
\hline Hold the MDI in a vertical position & $22(9.9)$ & $24(19.4)$ & 0.011 \\
\hline Hold your head in a vertical position & $22(9.9)$ & $25(20.2)$ & 0.007 \\
\hline Exhale before use & $169(75.8)$ & $85(68.5)$ & 0.092 \\
\hline Put the mouthpiece in your mouth, and close your lips & $39(17.5)$ & $23(18.5)$ & 0.456 \\
\hline Press the canister when inhaling slowly & $36(16.1)$ & $24(19.4)$ & 0.269 \\
\hline Inhale deeply & $96(43.0)$ & $48(38.7)$ & 0.251 \\
\hline Hold your breath for 10 seconds & $58(26.0)$ & $36(29.0)$ & 0.314 \\
\hline Exhale and wait for $30-60$ seconds before the other puff & $32(14.3)$ & $14(11.3)$ & 0.263 \\
\hline Instructions for Aerolizer ${ }^{\circledR} /$ Handihaler $^{\circledR}$ & COPD $(n=205)$ & Asthma $(n=78)$ & \\
\hline Pull off the Aerolizer cover & $20(9.8)$ & $12(15.4)$ & 0.131 \\
\hline Open the mouthpiece of Aerolizer & $20(9.8)$ & $11(14.1)$ & 0.200 \\
\hline Remove the capsule from the package and put it into the space & $27(13.2)$ & $14(17.9)$ & 0.201 \\
\hline Press the buttons on both sides of Aerolizer & $55(26.8)$ & $4 I(52.6)$ & 0.0005 \\
\hline Hold your head in a vertical position & $30(14.6)$ & $13(16.7)$ & 0.398 \\
\hline Turn your head away from Aerolizer and exhale & $150(73.2)$ & $56(71.8)$ & 0.463 \\
\hline Put the mouthpiece in your mouth, and close your lips & $26(12.7)$ & $12(15.4)$ & 0.338 \\
\hline Inhale deeply & $93(45.4)$ & $42(53.8)$ & 0.382 \\
\hline Hold your breath for 10 seconds & $40(19.5)$ & $26(33.3)$ & 0.012 \\
\hline Dispose of the capsule and put the cover back on the Aerolizer & $20(9.8)$ & $9(11.5)$ & 0.407 \\
\hline Instructions for Turbuhaler ${ }^{\circledR}$ & COPD $(n=32)$ & Asthma $(n=39)$ & \\
\hline Remove the cover & $2(6.3)$ & $8(20.5)$ & 0.082 \\
\hline Keep Turbuhaler upright & $2(6.3)$ & $10(25.6)$ & 0.029 \\
\hline Twist grip at the base; twist around and then back until click is heard & $5(15.6)$ & $8(20.5)$ & 0.415 \\
\hline Hold your head in a vertical position & $2(6.3)$ & $8(20.5)$ & 0.082 \\
\hline Exhale & $17(53.1)$ & $26(66.7)$ & 0.179 \\
\hline Put the mouthpiece in your mouth, and close your lips & $4(12.5)$ & $12(30.8)$ & 0.059 \\
\hline Breathe in strongly and deeply & $16(50.0)$ & $20(51.3)$ & 0.552 \\
\hline Hold your breath for 10 seconds & $10(31.3)$ & II (28.2) & 0.491 \\
\hline Breathe out gently & $3(9.4)$ & $7(17.9)$ & 0.247 \\
\hline Put the cover back and wait for 30-60 seconds for the second dose & $4(12.5)$ & $7(17.9)$ & 0.385 \\
\hline Instructions for Diskus ${ }^{\circledR}$ & COPD $(n=60)$ & Asthma $(n=65)$ & \\
\hline Open Diskus by pushing the thumb grip right around until it clicks & $15(25.0)$ & $18(27.7)$ & 0.446 \\
\hline Hold the mouthpiece toward you and push the lever away from you until it stops & $6(10.0)$ & $8(12.3)$ & 0.452 \\
\hline Exhale & $5(8.3)$ & $13(20.0)$ & 0.053 \\
\hline Hold your head in a vertical position & $8(13.3)$ & $14(2 \mid .5)$ & 0.167 \\
\hline Put the mouthpiece to your lips & $6(10.0)$ & $12(18.5)$ & 0.137 \\
\hline Breathe in strongly and deeply & $45(75.0)$ & $52(80.0)$ & 0.324 \\
\hline Remove your Diskus & $30(50.0)$ & $32(49.2)$ & 0.537 \\
\hline Hold your breath for 10 seconds & $22(36.7)$ & $21(32.3)$ & 0.373 \\
\hline Breathe out gently & II (I8.3) & $12(18.5)$ & 0.585 \\
\hline $\begin{array}{l}\text { Close Diskus by sliding the thumb grip back to the original position and wait for } \\
30-60 \text { seconds for the second dose }\end{array}$ & $10(16.7)$ & $4(6.2)$ & 0.057 \\
\hline
\end{tabular}

Notes: Chi-square test. Values in bold indicate statistical significance $(P<0.05)$.

Abbreviation: MDI, metered dose inhaler.

was associated with shorter duration of disease and inhaler therapy.

MDI-type inhalers were the most commonly used inhalers in both COPD and asthma patients in our cohort. However, past studies in patients with COPD and asthma revealed more prevalent usage of DPIs $(77.0 \%-78.9 \%)$ than MDI(12.0\%-16.8\%) type inhalers. ${ }^{13,17,19}$ This seems notable given that MDIs require a good ability of hand-lung coordination and is therefore considered to be inherently more difficult to use than DPIs. ${ }^{13,25,26}$ In fact, while considered to be more likely with MDI-type inhalers, ${ }^{9,15,27-29}$ suboptimal inhaler technique is very common in real life with both MDIs and DPIs, and in the majority of asthma and COPD patients, despite advances in inhaler device technology. $3,5,10-16$ 
Table 3 Sub-analysis of errors in inhaler techniques that differed between COPD and asthma groups

\begin{tabular}{|c|c|c|c|c|c|}
\hline & \multirow{2}{*}{$\begin{array}{l}\text { Age, } \\
\text { mean (SD) }\end{array}$} & \multicolumn{2}{|c|}{ Gender, n (\%) } & \multicolumn{2}{|c|}{ Duration (years), mean (SD) } \\
\hline & & Male & Female & Disease & $\begin{array}{l}\text { Inhaler } \\
\text { therapy }\end{array}$ \\
\hline \multicolumn{6}{|c|}{ Instructions for MDI } \\
\hline \multicolumn{6}{|c|}{ Take off the inhaler cap } \\
\hline Incorrect use & $57.9(10.5)$ & $17(10.0)$ & $19(10.7)$ & $8.8(8.8)$ & $7.5(6.6)$ \\
\hline Correct use & $62.4(13.0)$ & $153(90.0)$ & $158(89.3)$ & $9.8(8.2)$ & $8.1(7.1)$ \\
\hline$P$-value & 0.058 & \multicolumn{2}{|c|}{$0.48 I$} & 0.494 & 0.643 \\
\hline \multicolumn{6}{|c|}{ Hold the MDI in a vertical position } \\
\hline Incorrect use & $60.0(12.9)$ & $18(10.6)$ & $28(15.8)$ & $6.6(4.7)$ & $6.6(4.8)$ \\
\hline Correct use & $62.3(12.8)$ & $152(89.4)$ & $149(84.2)$ & $10.0(8.5)$ & $8.1(7.2)$ \\
\hline$P$-value & 0.275 & \multicolumn{2}{|c|}{0.100} & $<0.00$ I & 0.180 \\
\hline \multicolumn{6}{|c|}{ Hold your head in a vertical position } \\
\hline Incorrect use & $58.3(12.7)$ & $21(12.4)$ & $26(14.7)$ & $6.6(4.5)$ & $5.8(4.5)$ \\
\hline Correct use & $62.5(12.8)$ & $149(87.6)$ & $|5|(85.3)$ & $10.1(8.6)$ & $8.2(7.2)$ \\
\hline$P$-value & 0.044 & \multicolumn{2}{|c|}{0.316} & $<\mathbf{0 . 0 0 1}$ & 0.006 \\
\hline \multicolumn{6}{|c|}{ Instructions for Aerolizer ${ }^{\circledast} /$ Handihaler $^{\circledR}$} \\
\hline \multicolumn{6}{|c|}{ Press the buttons on both sides of device } \\
\hline Incorrect use & $63.2(12.0)$ & $4 I(27.0)$ & $55(42.0)$ & $10.0(8.9)$ & $8.3(8.1)$ \\
\hline Correct use & $64.0(10.5)$ & $111(73.0)$ & $76(58.0)$ & $10.1(8.5)$ & $8.2(7.0)$ \\
\hline$P$-value & 0.596 & \multicolumn{2}{|c|}{0.006} & 0.910 & 0.924 \\
\hline \multicolumn{6}{|c|}{ Hold your breath for 10 seconds } \\
\hline Incorrect use & $62.6(11.0)$ & $40(26.3)$ & $26(19.8)$ & $10.7(9.3)$ & $8.9(8.7)$ \\
\hline Correct use & $64.1(11.0)$ & $112(73.7)$ & $105(80.2)$ & $9.7(8.3)$ & $8.0(7.0)$ \\
\hline$P$-value & 0.344 & \multicolumn{2}{|c|}{0.127} & 0.425 & 0.421 \\
\hline \multicolumn{6}{|c|}{ Instructions for Turbuhaler ${ }^{\circledR}$} \\
\hline \multicolumn{6}{|c|}{ Keep inhaler upright } \\
\hline Incorrect use & $61.9(10.5)$ & $4(26.3)$ & $8(19.8)$ & $5.0(3.2)$ & $4.3(3.4)$ \\
\hline Correct use & $55.8(14.3)$ & $32(88.9)$ & 27 (77.I) & $9.5(8.9)$ & $8.2(7.4)$ \\
\hline$P$-value & 0.168 & \multicolumn{2}{|c|}{0.158} & 0.005 & 0.012 \\
\hline
\end{tabular}

Notes: Chi-square test, Student's $t$-test, Mann-Whitney $U$ test. Values in bold indicate statistical significance $(P<0.05)$.

Abbreviation: MDI, metered dose inhaler.

Overall, with no significant difference between COPD and asthma groups, the most common errors in inhaler technique for MDIs and DPIs in our cohort were failure to exhale before use of inhaler, followed by device-specific errors and failure to deeply inhale and to hold breath. In addition, errors related to device handling were common among MDI users than among DPI users. Likewise, failure to exhale before inhaling through device, inability to coordinate activation with inhalation, and failure to hold breath have also been reported to be errors in inhalation maneuvers that are common in all types of inhalers among COPD and asthma patients. ${ }^{13,17,30,31}$ In accordance with our findings, a high frequency of poor and/or suboptimal inhaler use has consistently been reported in past studies alongside a higher likelihood of errors related to device handling with use of MDIs compared with DPIs among COPD and asthma patients. ${ }^{9}, 15,29$

Past studies indicated either no difference between COPD and asthma patients in terms of inhaler technique ${ }^{17,19,32}$ or higher odds of incorrect inhaler technique in COPD patients attributed to older age and higher prevalence of comorbidities. ${ }^{8,28,33}$ Although the COPD patients were older than the asthma patients in our cohort, our findings revealed no significant difference between asthma and COPD patients in terms of basic inhalation maneuvers, whereas there was poorer inhaler technique in asthma than COPD patients, particularly in certain device-specific steps. Regarding the steps that significantly differed between asthma and COPD patients, a higher likelihood of incorrect technique was associated with shorter duration of disease and therapy for MDI and Turbuhaler ${ }^{\mathbb{B}}$ users, and with female gender for Aerolizer ${ }^{\mathbb{B} /}$ Handihaler ${ }^{\circledR}$ users. This seems to support the reported association of longer duration of therapy (repeated instructions over a period of time and regular follow-ups) $)^{14,34-36}$ with a proper inhaler technique ${ }^{37}$ as well as higher odds ratio of poor inhaler technique reported in females as compared to males. ${ }^{19}$

Indeed, with overconfidence of patients toward use of the device, a steep rise in number of errors with a longer duration of therapy has also been noted, emphasizing a need for 
regular instructions and intermittent checkups of inhalation techniques, given the increased number of errors. ${ }^{14}$ In addition, the preponderance of female patients in the asthma group compared to the COPD group in our cohort seemed to also be associated with the poorer inhaler technique noted among asthma patients with regard to certain device-specific maneuvers.

Hence, our findings support that structured and detailed education of patients on inhaler techniques should be an essential part of the pulmonary clinic practice. ${ }^{8}$ Past studies revealed a likelihood of incorrect use of inhaler devices even by medical personnel. ${ }^{38-41}$ In this regard, the sufficient ability of health care professionals themselves to use the inhaler devices and their awareness of all the correct steps and possible mistakes is considered to be of critical importance regarding the close follow-up of patients with repeated checking of inhaler techniques and correction of suboptimal techniques with tailored, in-depth support. ${ }^{3,14,34}$

The major strength of this study seems to be the comparative assessment of inhaler technique in a large-scale cohort of COPD vs asthma patients through direct observation of patients' performance in real-life clinical practice and by using checklists based on the manufacturers' instructions and national guidelines. However, certain limitations to this study should be considered. First, the cross-sectional design limits the interpretation of the findings and establishment of any cause and effect relationships. Second, inhaler technique was assessed based on frequently used type of inhalers, and several types of infrequently used inhalers could not be included in the analysis. Third, lack of data on past history of patient training in inhaler technique is another limitation which otherwise would have extended the knowledge gained in the current study.

\section{Conclusion}

In conclusion, our findings revealed that errors in inhaler technique in terms of inhalation maneuvers and device handling were similarly common in COPD and asthma patients. Errors in certain device handling maneuvers, particularly with MDIs, were more common among asthma patients than among COPD patients, and associated with female gender and shorter durations of disease and inhaler therapy. Our findings emphasize that suboptimal inhaler technique is common in real life for both MDIs and DPIs, emphasizing the potential role of regular assessment and reinforcement of correct inhalation technique in achieving treatment efficacy and improved disease outcomes.

\section{Disclosure}

The authors report no conflicts of interest in this work.

\section{References}

1. Cochrane MG, Bala MV, Downs KE, Mauskopf J, Ben-Joseph RH. Inhaled corticosteroids for asthma therapy: patient compliance, devices, and inhalation technique. Chest. 2000;117(2):542-550.

2. Virchow JC, Crompton GK, dal Negro R, et al. Importance of inhaler devices in the management of airway disease. Respir Med. 2008; 102(1):10-19.

3. Usmani OS, Lavorini F, Marshall J, et al. Critical inhaler errors in asthma and COPD: a systematic review of impact on health outcomes. Respir Res. 2018;19(1):10.

4. Pritchard JN. Industry guidance for the selection of a delivery system for the development of novel respiratory products. Expert Opin Drug Deliv. 2015;12(11):1755-1765.

5. Klijn SL, Hiligsmann M, Evers S, Román-Rodríguez M, van der Molen T, van Boven JFM. Effectiveness and success factors of educational inhaler technique interventions in asthma \& COPD patients: a systematic review. NPJ Prim Care Respir Med. 2017;27(1):24.

6. Lavorini F, Usmani OS. Correct inhalation technique is critical in achieving good asthma control. Prim Care Respir J. 2013;22(4):385-386.

7. Price D, Roche N, Christian Virchow J, et al. Device type and real-world effectiveness of asthma combination therapy: an observational study. Respir Med. 2011;105(10):1457-1466.

8. Khassawneh BY, Al-Ali MK, Alzoubi KH, et al. Handling of inhaler devices in actual pulmonary practice: metered-dose inhaler versus dry powder inhalers. Respir Care. 2008;53(3):324-328.

9. Molimard M, Raherison C, Lignot S, Depont F, Abouelfath A, Moore N. Assessment of handling of inhaler devices in real life: an observational study in 3811 patients in primary care. J Aerosol Med. 2003;16(3): 249-254.

10. Brocklebank D, Ram F, Wright J, et al. Comparison of the effectiveness of inhaler devices in asthma and chronic obstructive airways disease: a systematic review of the literature. Health Technol Assess. 2001; 5(26):1-149.

11. Leiva-Fernández F, Leiva-Fernández J, Zubeldia-Santoyo F, GarcíaRuiz A, Prados-Torres D, Barnestein-Fonseca P. Efficacy of two educational interventions about inhalation techniques in patients with chronic obstructive pulmonary disease (COPD). TECEPOC: study protocol for a partially randomized controlled trial (preference trial). Trials. 2012;13:64.

12. Purohit AN, Patel PP, Gandhi AM, Desai MK. An evaluation of impact of educational interventions on the technique of use of metered-dose inhaler by patients. Indian J Pharmacol. 2017;49(2):194-200.

13. Castel-Branco MM, Fontes A, Figueiredo IV. Identification of inhaler technique errors with a routine procedure in Portuguese community pharmacy. Pharm Pract. 2017;15(4):1072.

14. Arora P, Kumar L, Vohra V, et al. Evaluating the technique of using inhalation device in COPD and bronchial asthma patients. Respir Med. 2014;108(7):992-998.

15. Sanchis J, Gich I, Pedersen S. Aerosol Drug Management Improvement Team (ADMIT). Systematic review of errors in inhaler use: has patient technique improved over time? Chest. 2016;150:394-406.

16. Ganguly A, das AK, Roy A, Adhikari A, Banerjee J, Sen S. Study of Proper use of Inhalational Devices by Bronchial Asthma or COPD Patients Attending a Tertiary Care Hospital. J Clin Diagn Res. 2014; 8(10):HC04.

17. Melani AS, Bonavia M, Cilenti V, et al. Gruppo Educazionale Associazione Italiana Pneumologi Ospedalieri. Inhaler mishandling remains common in real life and is associated with reduced disease control. Respir Med. 2011;105:930-938.

18. Sanchis J, Corrigan C, Levy ML, Viejo JL, ADMIT Group. Inhaler devices - from theory to practice. Respir Med. 2013;107(4):495-502. 
19. Chorão P, Pereira AM, Fonseca JA. Inhaler devices in asthma and COPD - an assessment of inhaler technique and patient preferences. Respir Med. 2014;108(7):968-975.

20. Global initiative for chronic obstructive lung disease. Pocket guide to COPD diagnosis, management and prevention. Available from: http:// goldcopd.org/wp-content/uploads/2016/12/wms-GOLD-2017-PocketGuide.pdf. Accessed December 12, 2017.

21. Global initiative for asthma. Pocket guide for asthma management and prevention. Available from: http://ginasthma.org/2017-pocket-guidefor-asthmamanagement-and-prevention/. Accessed October 8, 2017.

22. Josef Micallef J, Micallef LA, Gouder C. Comparison of asthma and COPD patients' perception of appropriate metered-dose inhaler technique with a questionnaire and supervision based reference standard. Eur Resp J. 2014;44:401.

23. Turkish Thoracic Society. Living with Asthma. Patient Information Handbook. Erdinc M, Gulmez I, editors. Istanbul, Turkey: Aves Publications; 2009. Available from: http://toraks.org.tr/userfiles/ file/02_Astimla_yasam.pdf

24. Turkish Thoracic Society Asthma Diagnosis and Management Guidelines 2016 update. Turkish Thoracic J. 2016;17(Suppl 1): 1-108. Available from: http://www.toraks.org.tr/uploadFiles/book/ file/1082017TTD-Astim-Tani-ve-Tedavi-Rehberi-2016.pdf. Accessed January 25, 2018

25. Rootmensen GN, van Keimpema AR, Jansen HM, de Haan RJ. Predictors of incorrect inhalation technique in patients with asthma or COPD: a study using a validated videotaped scoring method. J Aerosol Med Pulm Drug Deliv. 2010;23(5):323-328.

26. Pothirat C, Chaiwong W, Phetsuk N, Pisalthanapuna S, Chetsadaphan N, Choomuang W. Evaluating inhaler use technique in COPD patients. Int J Chron Obstruct Pulmon Dis. 2015;10:1291-1298.

27. Al Ammari M, Sultana K, Yunus F, Al Ghobain M, Al Halwan SM. A cross-sectional observational study to assess inhaler technique in Saudi hospitalized patients with asthma and chronic obstructive pulmonary disease. Saudi Med J. 2016;37(5):570-574.

28. Souza ML, Meneghini AC, Ferraz E, Vianna EO, Borges MC. Knowledge of and technique for using inhalation devices among asthma patients and COPD patients. J Bras Pneumol. 2009;35(9):824-831.

29. Takaku Y, Kurashima K, Ohta C, et al. How many instructions are required to correct inhalation errors in patients with asthma and chronic obstructive pulmonary disease? Respir Med. 2017;123:110-115.
30. Lavorini F, Magnan A, Dubus JC, et al. Effect of incorrect use of dry powder inhalers on management of patients with asthma and COPD. Respir Med. 2008;102(4):593-604.

31. García-Cárdenas V, Sabater-Hernández D, García-Corpas JP, Faus MJ, Martínez-Martínez F, Benrimoj SI. Errors in Turbuhaler technique in a Spanish population of asthmatic patients. Respir Care. 2012;57(5): $817-818$.

32. Press VG, Arora VM, Shah LM, et al. Misuse of respiratory inhalers in hospitalized patients with asthma or COPD. J Gen Intern Med. 2011;26(6):635-642.

33. Lavorini F, Mannini C, Chellini E, Fontana GA. Optimising inhaled pharmacotherapy for elderly patients with chronic obstructive pulmonary disease: the importance of delivery devices. Drugs Aging. 2016; 33(7):461-473.

34. Y1ldı F, Group AS, ASIT Study Group. Factors influencing asthma control: results of a real-life prospective observational asthma inhaler treatment (ASIT) study. J Asthma Allergy. 2013;6:93-101.

35. Gracia-Antequera M, Morales Suárez-Varela M. An intervention to improve the inhalatory technique of children and adolescents with asthma. Allergol Immunopathol. 1999;27(5):255-260.

36. Al-Jahdali H, Ahmed A, Al-Harbi A, et al. Improper inhaler technique is associated with poor asthma control and frequent emergency department visits. Allergy Asthma Clin Immunol. 2013;9(1):8.

37. Sen E, Gonullu U, Ekici Z, Kursun N. Assessment of inhaler technique and treatment compliance of hospitalized patients and outpatients in a university hospital. J Ankara Univ Fac Med. 2006;59:1-6.

38. Plaza V, Sanchis J. Medical personnel and patient skill in the use of metered dose inhalers: a multicentric study. CESEA Group. Respiration. 1998;65(3):195-198.

39. Hanania NA, Wittman R, Kesten S, Chapman KR. Medical personnel's knowledge of and ability to use inhaling devices. Metered-dose inhalers, spacing chambers, and breath-actuated dry powder inhalers. Chest. 1994;105(1):111-116.

40. Guidry GG, Brown WD, Stogner SW, George RB. Incorrect use of metered dose inhalers by medical personnel. Chest. 1992;101(1):31-33.

41. Lee-Wong M, Mayo PH. Results of a programme to improve house staff use of metered dose inhalers and spacers. Postgrad Med J. 2003; 79(930):221-225.
International Journal of COPD

\section{Publish your work in this journal}

The International Journal of COPD is an international, peer-reviewed journal of therapeutics and pharmacology focusing on concise rapid reporting of clinical studies and reviews in COPD. Special focus is given to the pathophysiological processes underlying the disease, intervention programs, patient focused education, and self management protocols.

\section{Dovepress}

This journal is indexed on PubMed Central, MedLine and CAS. The manuscript management system is completely online and includes a very quick and fair peer-review system, which is all easy to use. Visit http://www.dovepress.com/testimonials.php to read real quotes from published authors. 